hyperalgesia. Furthermore, they suggested that remifentanil in association with ketamine was useful in patients pretreated with opioids.

One possibility for this patient's pain in the postoperative period - and in our view the most likely one - however is not discussed, namely opioidwithdrawal hyperalgesia. Postoperative analgesia in patients who receive opioids for chronic pain is undoubtedly a challenge for anaesthesiologists and pain therapists. In clinical practice, chronic pain patients receiving strong opioids preoperatively show high inter-individual variability and sometimes extremely high postoperative demand for opioids. Depending on the chronic opioid dose, total cumulative doses of $30-45 \mathrm{mg}$ piritramide within the first $1-2 \mathrm{~h}$ are common in these patients. These observations are in accordance with Rapp and colleagues [2], who found a more than three-fold $(135.8 \mathrm{vs} .42 .8 \mathrm{mg}$ ) increase in opioid demand in the first $24 \mathrm{~h}$ after surgery in patients with preoperative opioid consumption as compared with opioid-naïve patients.

In addition, we feel that postoperative analgesia is much more difficult to handle in chronic pain patients receiving remifentanil as sole opioid intraoperatively as compared with those receiving long-acting $\mu$-opioid agonists like fentanyl or sufentanil. Irrespective of the fact whether this patient's fentanyl patch was removed before surgery or not, we feel that the administration of $10 \mathrm{mg}$ piritramide and $4 \mathrm{mg}$ morphine for postoperative analgesia in this patient was simply not enough to provide sufficient analgesia.
It has been shown that enhanced pain sensations after cessation of a remifentanil infusion are due to an acute withdrawal response, which cannot be modulated by $N$-methyl-D-aspartic acid receptor antagonists $[3,4]$. Therefore, we think that the therapeutic effect of ketamine observed by Dumont and colleagues is most likely due to its direct analgesic or hypnotic effect and not based on the reversal of pronociceptive mechanisms induced by remifentanil. The increasing evidence for opioid-induced hyperalgesia should not lead to a restricted use of opioids in the perioperative period, especially not in patients who have a history of chronic opioid administration.

\section{A. Z. Tzabazis, W. Koppert Anästhesiologische Klinik Universitä̈tklinikum Erlangen Germany}

\section{References}

1. Dumont H, Guntz E, Sosnowski M, Talla G. Opioid-induced hyperalgesia. Eur J Anaesthesiol 2007; 24(2): 205-207.

2. Rapp SE, Ready LB, Nessly ML. Acute pain management in patients with prior opioid consumption: a case-controlled retrospective review. Pain 1995; 61(2): 195-201.

3. Koppert W, Sittl R, Scheuber K, Alsheimer M, Schmelz M, Schuttler J. Differential modulation of remifentanil-induced analgesia and postinfusion hyperalgesia by S-ketamine and clonidine in humans. Anesthesiology 2003; 99: 152-159.

4. Koppert W, Angst M, Alsheimer $\mathrm{M}$ et al. Naloxone provokes similar pain facilitation as observed after shortterm infusion of remifentanil in humans. Pain 2003; 106(1-2): 91-99.

\title{
Comparison of LMA Unique, Ambu laryngeal mask and Soft Seal laryngeal mask during routine surgical procedures
}

\author{
doi: $10.1017 / S 0265021507000518$
}

\section{EDITOR:}

We read with interest the paper by Francksen and colleagues [1] comparing the LMA Unique, Ambu laryngeal mask and Soft Seal laryngeal mask. In a randomized controlled study, we compared the

Correspondence to: Baha Al-Shaikh, Department of Anaesthesia, William Harvey Hospital, Kennington Road, Ashford, Kent TN24 OLZ Ashford, UK. E-mail: bal_shaikh@yahoo.com; Tel: +1233 633331, ext 86041

Accepted for publication 11 March 2007 EJA 4468

First published online 7 June 2007 performance of the LMA Unique with the Soft Seal laryngeal mask and the Cobra Perilaryngeal Airway [2]. We studied 320 consecutive patients in the three groups and found that the LMA Unique and Soft Seal laryngeal mask were of equal clinical performance. Ease of insertion between the two devices was very similar using a partially inflated cuff. In the Unique LMA group, a successful primary airway was established in $96 \%$ of patients on the first attempt, and in $4 \%$ of patients insertion failed at the second attempt. In the Soft Seal 
laryngeal mask group, a successful primary airway was established in $99 \%$ of patients on the first attempt, and in $1 \%$ of patients insertion failed at the second attempt. In agreement with the authors, the effective airway time was similar for the two devices and the oropharyngeal leak pressure was higher in the Soft Seal laryngeal mask group. The endoscopic score of the larynx was significantly better with the Soft Seal laryngeal mask group than with the Unique LMA group. The changes in cuff pressures and airway morbidity were similar in both groups.

In an observational study, we inserted the Soft Seal laryngeal mask with the cuff inflated at atmospheric pressure [3] in 100 patients and achieved $97 \%$ success in the first attempt and $3 \%$ in the second attempt. Regarding insertions, 85\% were graded as very easy and $12 \%$ as easy and were achieved within $20 \mathrm{~s}$. The mean intra-cuff pressure in vivo was $40 \mathrm{mmHg}\left(53 \mathrm{~cm} \mathrm{H} \mathrm{H}_{2} \mathrm{O}\right)$. The leak pressure was at a mean pressure of $24.8 \mathrm{~cm} \mathrm{H}_{2} \mathrm{O}$, in agreement with the authors. Only six patients complained of mild-to-moderate sore throat in the first $2 \mathrm{~h}$ after operation.

We agree with the authors' conclusion that the LMA Unique and the Soft Seal laryngeal mask are of equal clinical suitability. We believe that inserting the Soft Seal laryngeal mask with the cuff inflated at atmospheric pressure can achieve excellent conditions for insertion and removal.

B. Al-Shaikh, V. Dixit Department of Anaesthesia William Harvey Hospital

Ashford

Kent, UK

A. van Zundert

Department of Anesthesiology

Catharina Hospital

The Netberlands

\section{References}

1. Francksen H, Bein B, Cavus E et al. Comparison of LMA Unique, Ambu laryngeal mask and Soft Seal laryngeal mask during routine surgical procedures. Eur $J$ Anaesthesiology 2007; 24: 134-140.

2. van Zundert AAJ, Al-Shaikh B, Brimacombe J, Koster J, Koning D, Mortier EP. Comparison of three disposable extraglottic airway devices in spontaneously breathing adults: the LMA-Unique [TM], the Soft Seal laryngeal mask, and the Cobra perilaryngeal airway. Anestbesiology 2006; 104(6): 1165-1169.

3. Al-Shaikh B, George William M, Van Zundert AAJ. Using atmospheric pressure to inflate the cuff of the Portex laryngeal mask. Anasthesia 2005; 60: 287-297.

\section{Conditions involving release of pro-inflammatory cytokines predispose to ARDS}

doi: $10.1017 / \mathrm{S} 026502150700049 \mathrm{X}$

\section{EDITOR:}

Sadis and colleagues [1] investigated risk factors for the development of ARDS in parients receiving multiple transfusions and found that it was not the number of transfusions but thoracic trauma and hypoxia that were associated with the subsequent development of ARDS. Patients who developed ARDS received significantly more fresh frozen plasma. Previous studies showed that septicaemia is an additional predisposing factor for transfusionrelated ARDS [2]. Another condition commonly

Correspondence to: Michael Eisenhut, Luton and Dunstable Hospital NHS Foundation Trust, Luton, Bedfordshire, LU4 ODZ, UK. E-mail: michael_ eisenhut@yahoo.com; Tel: +0845 1270127; Fax: +1582 497280

Accepted for publication 12 March 2007 EJA 4369

First published online 7 June 2007 associated with pulmonary oedema during infusion of large amounts of intravenous fluids is diabetic ketoacidosis [3]. All these conditions with their different pathophysiology have in common the release of large amounts of cytokines including tumour necrosis factor (TNF) and interleukin-1 (IL-1). Transfusion of an anti-CD28 monoclonal antibody into human volunteers stimulated T-cells to release large amounts of these two cytokines and led to pulmonary oedema in all subjects of this trial [4]. The mechanism by which these cytokines lead to or predispose to pulmonary oedema has recently been clarified: Alveolar epithelial fluid clearance in pulmonary oedema is dependent on pulmonary epithelial sodium and chloride transport through the apical alveolar epithelial sodium channel and the cystic fibrosis transmembrane conductance 
Copyright of European Journal of Anaesthesiology is the property of Cambridge University Press / UK and its content may not be copied or emailed to multiple sites or posted to a listserv without the copyright holder's express written permission. However, users may print, download, or email articles for individual use. 